\title{
SOME PRELIMINARY REMARKS ON THE ORIGINS OF PRAGMATISM
}

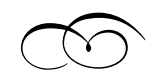

W

hen James named "pragmatism" in 1898, he gave life to a new intellectual phenomenon in American culture. Though Charles Peirce had provided the groundwork for this new phenomenon some twenty years earlier, it was not until James named it that pragmatism became a matter of controversy and interest for a much wider intellectual community. ${ }^{1}$ Between 1900 and 1916 many rallied behind the new outlook, giving it definition and purchase, while others vehemently opposed its apparent relativistic and subjectivistic traits. For most of the twentieth century, pragmatism remained in a somewhat dormant state, kept alive by Dewey's longevity and a relatively small philosophical culture that was for the most part overshadowed by the dominance of analytic philosophy. Thinkers such as Herbert Schneider, Joseph Blau, Robert Pollock, John E. Smith, Thelma Lavine, John McDermott, Sidney Ratner, Carl Hausman, Sandra Rosenthal, Richard Bernstein, Beth Singer, and John Lachs kept the pragmatic tradition alive and well, but it became highly visi- 
ble to the analytic tradition only when, in the 1980s, Richard Rorty, drawing on his own selected readings of James and Dewey, confronted that tradition with its own glaring limitations.

This so-called neopragmatic movement brought new readers to the texts of Peirce, Schiller, James, and Dewey, even as those steeped in the history of pragmatism and American thought continued to develop their much richer accounts of the pragmatic tradition. In the chapter at hand, I want to explore briefly the origins of pragmatism between 1898 and 1916. My suspicion is that pragmatism, because James and Dewey took it outside the bounds of professional philosophy, has had a much wider cultural impact in the United States than has most of the rest of philosophy in America. James brought pragmatism to religion, to humanistic psychology, and to the sociology of science. Peirce influenced notions of scientific method, legal interpretation, and linguistic analysis. And Dewey, perhaps most effectively of all, brought pragmatism to mainstream American culture through his work in education, political practice, and even aesthetic practice by way of his work with the Barnes Foundation. In short, much of our cultural inheritance from the twentieth century is shot through with pragmatic features even if they have not been recognized as such. If this is so, taking a quick look at the origins of pragmatism may help us to see where these pragmatic features reside and where pragmatic thought might be helpful in assessing what we do as a human community. Moreover, as I have argued elsewhere, pragmatism did not appear from nowhere; it bears the marks of American Transcendentalism and later nineteenth-century idealism. Thus, exploring its origins may give us some idea of how these traditions have found their way into the fabric of our cultural meaning.

What one finds in the origins of pragmatism depends in some measure on how one looks. Those of us who study American philosophy have come to focus on the differences among Peirce, James, Dewey, and Royce as we have become specialists in their respective outlooks. But when we look at the origins, we see that they shared some basic interests and beliefs. Peirce suggested to F. C. S. Schiller that pragmatism be defined around these commonalities but be left 
open to develop: "I would let it grow and then say it is what a certain group of thinkers who seem to understand one another think, and thus make it the name of a natural class in the Natural History fashion" (MS L390, p. 3). The emphasis on experimental method appears across the board. So, too, do emphases on consequences, the reconstruction of the idea of truth, and the importance of evolutionary thinking. Other items are shared on a more limited basis. James, Schiller, and Dewey, following the trajectory of the Transcendentalists, focus on the conduct of life. James, Royce, and Peirce retain an interest in the religious dimension of human experience. Peirce, Royce, and Dewey emphatically defend a realism of ideas that sees philosophical ideals as crucial to the development of social and intellectual traditions. We can also look past specific philosophical content to find temperamental affinities among the pragmatists. They went at life and philosophy wholeheartedly and seldom cautiously; however, with the exception of Royce, they were not absolutists. They were deeply committed to transforming the culture in which they found themselves. James and Dewey explicitly described themselves as meliorists. They also thought with abandon, sharing a philosophical attitude that included an element of spontaneity. The philosophical corollary to this attitude was their shared belief in the unbridling of the cosmos; the world was for them no longer a static, steady-state system, but a partially organized, evolving, and spontaneously developing nature.

This unbridling of the cosmos appears in Peirce's tychism, in James's recurrent appeals to risk, and in Dewey's attentiveness to the Darwinian fascination with change. The original pragmatic attitude, appropriating the mystery but rejecting the necessity of Hellenic fate, is about the gambling nature of human endeavor. This means it is also about a willingness to countenance the possibility of failure, loss, and losing. In ways different from both stoicism and existentialism, pragmatism asks us to accept the reality of loss. The Stoics called for an acquiescent acceptance of loss, and the existentialists often coupled loss with a sense of disempowerment. Pragmatism aims at what James called "the strenuous mood" even in the face of loss. In this 
strenuous mood, pragmatism deals with ways to handle such an unstable environment, looking for ways to stack the cultural deck in favor of social stability. Each of the originators offers us a different avenue, through inquiry, toward such stability. But behind the solutions is the unbridled cosmos itself. James, trying to sober the tender thinkers and awaken the tough ones, makes a plea for the recognition of our gambling ways:

I find myself willing to take the universe to be really dangerous and adventurous, without therefore backing out and crying "no play." I am willing to think that the prodigal-son attitude, open to us as it is in many vicissitudes, is not the right and final attitude towards the whole of life. I am willing that there should be real losses and real losers, and not total preservation of all that is. I can believe in the ideal as an ultimate, not as an origin, and as an extract, not the whole. When the cup is poured off, the dregs are left behind forever, but the possibility of what is poured off is sweet enough to accept. ${ }^{2}$

Here, as elsewhere, James pushed almost to the point of claiming an aesthetic importance for evil; it conditions the gambler's interest in the playing of the game. In "What Makes Life Significant" James recalls his summer visit to the upper-middle-class paradise of Chautauqua, New York, only to awaken to its suffocating pleasantness and seek out some "reality" in the lives of steelworkers and "peasant" farmers. For James, a perfect world given to us with no effort on our part, with no strenuous engagement, is not worth having. If this seems an unnecessarily strong prescription, we might think of James as working in a Thoreau-like manner, overstating his prescriptive claim just to awaken us to the description he thinks we may have forgotten or lost sight of - that our world is shot through with risk in all its dimensions. Pluralism is a good, but a good in which there are seams, holes, and cracks where things may fall through unnoticed, unsupported, and, perhaps ultimately, unredeemed.

With Peirce and Dewey the acceptance of loss is less clear. Each openly states up front his commitment to the openness of the future of the cosmos. Peirce admits spontaneity as a "character of the uni- 
verse," adding that "Everywhere the main fact is growth and increasing complexity" (EP, 1:308). Likewise Dewey, who also focuses on the stabilities of experience, states, "The world is precarious and perilous" (LW, 1:44). However, their openness to loss is less apparent than is the case with James, perhaps because each is intent, in a different way, on patching the cosmic rents that have been made manifest: Peirce through a developmental teleology that increases order and Dewey through the application of "intelligence" to cultural problems. Peirce's world is, like Royce's, made whole again in the infinite long run, and Dewey's is given the possibility of significant stability in the short run. It seems on occasion almost as if they make a presentation of the problematic situations in order to make room for their elaborate descriptions of a new method of inquiry in which pragmatism plays a featured role. In the most cynical reading, Dewey's instrumentalism is a social fix-it machine and Peirce's dynamic idealism is simply a postdated absolutism. Their quick turn to cures, however, may be misleading-if we read more widely, we can capture their recognition of lived instability and the gambling nature of belief.

Recall the emphasis each places on the experimental method. Peirce makes his "scientific" method the centerpiece of his early pragmatism in "The Fixation of Belief." Dewey sees experimentalism as the very key to education in "Experiment in Education": "For the present, the greatest contribution which any experimental school can make to education is precisely the idea of experiment itself, the ideal of the experimental method as the spirit in which a social problem is to be approached" (MW, 10:123). On the one hand, their faith in the success of the method yields a generally hopeful outlook-a pragmatic optimism. On the other hand, the admission of experiment reveals the presence of failure and loss; to experiment is to expect in some instances to fail or to lose-and for someone, perhaps someone other than the experimenter, to learn from losing. "For fallibilism is the doctrine," Peirce says, "that our knowledge is never absolute but swims, as it were, in a continuum of uncertainty and of indeterminacy" (CP 1:171). If we think back to "The Fixation of Belief," we can see this pragmatic attitude of gambling with the uncertainties con- 
joined directly with philosophical logic. In the essay Peirce, as a philosopher, provides those of us interested in logic and science with a reasonably persuasive transcendental hypothesis in favor of the scientific method: If we desire true belief and the overcoming of doubt, we must accept something like his experimental method of inquiry. But Peirce, perhaps sensing the instability of his own argumentation, closes the essay with a James-like appeal to pragmatic choice:

But she [scientific method] is the one that he [Peirce, we suspect] has chosen, and he knows that he was right in making that choice. And having made it, he will work for her, and will not complain that there are blows to take, hoping that there may be as many and as hard to give, and will strive to be the worthy knight and champion of her from the blaze of whose splendours he draws his inspiration and his courage. (EP, 1:123)

Whatever the logic of the situation, there remains an existential uncertainty. Clearly Peirce is not interested in losing; but it is also clear that he sees the possibility of loss to the other methods of inquiry - tenacity, authority, and apriorism—all of which bear marks of being arbitrary and contingent. He may lose in one of two ways. There may be blows to take, first, from within the method. That is, the experimental method expects us to fail some percentage of the time; and however much we learn from failure, its experience is usually disheartening and unsettling, and is never consummatory. There may also be blows to take from outside the method, from those who champion the other methods, whose advantages Peirce was not able simply to dismiss. The philosophical life-the logical, scientific, experimental life-as Socrates well knew, and as Peirce in his own dismal existence was never allowed to forget, lives constantly under threat. There is never a shortage of dogmatic believers from every political corner who will find excuses to close the avenues of inquiry.

Dewey stands in an equally puzzling place. Perhaps the most common charge leveled against him is that his thinking is absurdly utopian and optimistic, hinging always on an unforgivable belief in the capacity of human beings to handle their own affairs. These sorts of 
complaints are lodged against a philosopher who believed he was overcoming the Romantic visions of the nineteenth century. Where are failure, loss, and losing to be found in such a happy outlook? In his later career, after the complaints had been lodged, Dewey took pains to address this charge of innocence, especially, for example, in the opening chapters of Experience and Nature, where he says, "We confine ourselves to one outstanding fact: that evidence that the world of empirical things includes the uncertain, unpredictable, uncontrollable, and hazardous" (LW, 1:43). Thus, we should not remain blind to the presence of loss in the origins of Dewey's own pragmatism. In Democracy and Education, taking a cue from his reading of both Peirce and James, Dewey takes education to be the essential weapon in the combat with social risks. Yet, he recognizes the very fragility of the educative process, which is in all its features historically and socially contexted. In an interesting dialogue in 1906, Dewey resists the Augustinian suppression of evil:

Drop the presupposition that you read into everything I say, the idea that the reality of things as they are is dependent upon something beyond and behind, and the facts of the case just stare you in the eyes: Goods are, a multitude of them-but, unfortunately, evils also are; and all grades, pretty much, of both. (MW, 4:19)

There is no Jamesian valorization of evil to awaken us, but Dewey reminds us that we feel evils, we feel failures and losses. These are natural and human experiences: "I don't need an absolute to enable me to distinguish between, say, the good of kindness and the evil of slander, or the good of health and the evil of valetudinarianism" (MW, 4:20). For Dewey, primary experience is shot through with existential lessons in human living.

In looking more widely at the early criticisms of pragmatism, we find a variety of takes: it had no doctrine, it was not systematic, it was relativistic, and so forth. But the most widespread-and perhaps the most descriptively accurate-complaint was that pragmatism was too personal, too experiential, too much a function of and too closely aimed at the conduct of life. Indeed, Dewey famously supplies "a 
first-rate test of the value of any philosophy": "Does it end in conclusions which, when they are referred back to ordinary life-experiences and their predicaments, render them more significant, more luminous to us, and make our dealings with them more fruitful?" (LW, 1:18). In 1907, referring obliquely to the birth of pragmatism, J. E. Creighton said in a speech to the APA: "At the present time the danger rather lies in a tendency to adopt an individual and external mode of philosophizing, which may properly enough be described as that of the essayist." 3 Looking backward, Creighton aimed at excommunicating from "philosophy proper" the literary features of Plato, Augustine's autobiographical work, and European humanism, as well as the predecessors of pragmatism and existentialism, including Emerson, Fuller, Nietzsche, Kierkegaard, and Thoreau. Looking forward, he foreshadowed the narrowly confining control of "philosophy proper" by the Anglo-American analytic school that excluded existentialism and phenomenology as well as pragmatism. Despite the impact of Richard Rorty's Philosophy and the Mirror of Nature, this controlling attitude is still alive and well in many quarters.

Creighton further developed his worry about the pragmatic "essayist":

He may say a great many wise and illuminating things, and even point out facts and relations which must be taken account of in any philosophical treatment of the subject. But his results should not be mistaken for philosophy. For the essayist does not attempt to organize his results according to any logical principle or to develop them to a systematic conclusion. ${ }^{4}$

Creighton marks the dissociation between philosophy and wisdom (both sophia and phronesis) that came to dominate twentieth-century thought as philosophy was scientized. Ironically, for Creighton and the analytic schools, "logical principle" and "systematic conclusion" are code words for deductivism. Instead of making philosophy scientific, the new scientistic philosophers returned to and relied on an almost medieval understanding of philosophical argument.

Indeed, the pragmatist "essayist's" primary goal was to replace deductivism with an experimental method that more generally paral- 
leled scientific reasoning. As we just noted, this is specifically addressed in "The Fixation of Belief," the original publication in the pragmatic tradition. Peirce argued against apriorism not only because it claimed to be intuitive in a strong sense but also because it inevitably led to closed systems of belief that were generated by deduction from a single initial premise. Dewey, too, openly and endlessly brought experimentalism to human inquiry in all fields. It may be that Creighton's primary target was James, but this, too, is problematic, since James developed and employed his radical empiricism precisely to highlight the unscientific limitations that traditional empirical philosophies placed on inquiry.

Peirce actively regarded Creighton's deductivist understanding of science to be misguided; Peirce saw science as a method of inquiry, not as a body of knowledge. "Science," he argued, "is defined as a body of knowledge. But it is not half so much knowledge as inquirythe active wanting to know which implies we don't already,- that makes the scientific man" (MS 866, p. 4). From Peirce's perspective, then, Creighton, like many critics of pragmatism, misconceived both science and pragmatism: "In the first place, philosophy, like all other genuine sciences, has passed beyond the stage of the merely striking or suggestive treatment of problems, and aims not at interesting or picturesque results, but at the systematic organization of the facts with which it deals according to some general principle." 5 Systematic organization was at best, for Peirce, a small part of a scientist's practice. Despite the fact that the sciences are still often taught as bodies of knowledge, any close examination of what scientists do will reveal that the pragmatists are much closer to describing a "scientific" philosophy than were Creighton, Reichenbach, Carnap, and Karl Pearson.

If the pragmatists defended a method that led to a developmental conception of truth and wisdom, at the practical level they carried out similar projects. All their talk of risk, experiment, hypothesis, and experiential testing could be applied to practice as well as to theoryindeed, from one angle of vision they can be seen as applying their ideas to the practice of theorizing. Following their understanding of 
Aristotle, the pragmatists believed good philosophy must have a practical dimension, or what James often called a "cash value." They were not Enlightenment believers in the inevitability of progress, but across the board the pragmatists were meliorists. They believed that inquiry and experiment could lead to the betterment of human existence.

Although James and Dewey were the most explicit in asserting a melioristic outlook, Peirce's conception of truth is the model on which all the pragmatic meliorisms are based. By 1902 Peirce had arrived at his belief that logic, like aesthetics and ethics, is a normative science whose ultimate aim is truth. Thus, his abductive, or hypothesis-driven, scientific method, which he laid out in a series of lectures in 1903 , is a description of the human ability to pursue truth in a way that is self-correcting. In short, truth can get better. Contrary to the notions of some commentators, Peirce never stated that truth will be achieved; rather, as Cheryl Misak points out, truth is an ideal at which inquiry aims. "True beliefs," she says, "are those which would, in the end, get along with experience and one explanation of our beliefs achieving more and more fit with experience is that a good number of them are true. ... The ground upon which inquiry walks is tenuous and it is only the danger of losing our footing that makes us go forward."' Thus, truth may get "better" in human history, but without any anticipation of actually encountering a final "best" truth. Alfred Sidgwick put the point well in a discussion article in Mind in 1908: "The anti-pragmatist still dreams of an eternal and unassailable truth, while the pragmatist (like the man of science) sees our human need of putting up with truth which has its day and then gets lost in fuller explanations."7 As Vincent Potter points out, "Peirce sees and explicitly says that there are 'practical sciences of reasoning and investigation, of the conduct of life, and of the production of works of art' (5:125) which correspond to the normative sciences, 'and may be probably expected to receive aid from them' (5:125)."' It was within the spirit of this last claim that both James and Dewey worked. Each in his own way applied the developmental conception of inquiry not only to truth but also to moral, practical, and political goods. 
As a normative science, ethics seeks the good in conduct. But without an immediate knowledge of the absolute good, we humans are left to find our experiential problems and to try to improve. As James put it in "The Moral Philosopher and the Moral Life": "Every real dilemma is in literal strictness a unique situation: and the exact combination of ideals realized and ideals disappointed which each decision creates is always a universe without precedent, and for which no adequate previous rule exists." 9 Dewey works this pragmatic casuistry out in more detail, suggesting that we create "hypotheses" of betterness for any given situation, and that we try out these hypotheses both in imaginative dramatic rehearsals and in actual practice. We experiment and return to our actual "had" experiences to find out what "works" - what is better-and what does not.

This meliorism, whether of truth or the good, is a centralperhaps the central-belief shared by all the pragmatists in the early years of pragmatism's career. William Mackintire Salter, in his 1908 essay "Pragmatism: A New Philosophy," saw much more clearly than did Creighton what was afoot in the origins of pragmatism. Of the pragmatists' ideas of science, religion, and morality, he claimed: "They are working truths rather than finalities- the best to date, and yet liable to be superseded by something that will work better." 10

The experimentalism, the emphasis on risk, the belief in being able to "better" our present situations are all indications that, in its origin, pragmatism was a philosophy of hope. Hope was the mood or temperament governing Peirce's faith in science, Dewey's faith in education, and James's faith in the human spirit. This hopefulness was considered by many to be, in James's language, tender-minded or sentimental. Paul Carus, who published the work of the pragmatists but resisted them relentlessly, wrote disparagingly of them as "sentimentalists." And sentimentalists, he argued, "who are incapable of logical reasoning whenever their feelings are engaged are pathological." 11 Even Peirce, the most mathematically inclined and technically oriented of the pragmatists, included himself among the class of sentimentalists when it comes to the conduct of life: "Reason, then, appeals to sentiment in the last resort. Sentiment on its side feels itself 
to be the man. That is my simple apology for philosophical sentimentalism" (CP, 1:632). Carus and the antipragmatists, stuck as they were in a deductivist account of philosophical method and system, could not see the experiential truth of James's "Sentiment of Rationality": "As soon ... as we are enabled from any cause whatever to think with perfect fluency, the thing we think of seems to us pro tanto rational."12 Reasoning, insofar as it to some extent hinges on sentiment and feeling, is a gamble-pragmatic hope acknowledges the risks, the sentiment, the faith, and moves forward. It is fallibilistic and accepts the risks involved.

Furthermore, as with Peirce, not only science but also the activity of philosophizing itself bears the marks of a gambling way of life. Dewey does not allow philosophers to escape to an unassailable platform from which to snipe at the rest of the community or from which to gloss over the degeneracies of our environment. In the concluding paragraph of "Does Reality Possess Practical Character?" we find another of those peculiarly pragmatic appeals that we have come to associate with James but that in the work of Dewey and Peirce we tend to forget:

Under such circumstances there is danger that the philosophy which tries to escape the form of generation by taking refuge under the form of eternity will only come under the form of a bygone generation. To try to escape from the snares and pitfalls of time by recourse to traditional problems and interests-rather than let the dead bury their own dead. Better it is for philosophy to err in active participation in the living struggles and issues of its own age and times than to maintain an immune monastic impeccability, without relevancy and bearing in the generating ideas of its contemporary present. (MW, 4:142)

Dewey here lays out the most important feature of the pragmatic attitude of hope and loss for pragmatism's own philosophical future, which is now our philosophical present. Pragmatism, as philosophical school, must be willing to lose, perhaps altogether, but assuredly at least strands of whatever cables of belief it develops. The preservation of the origins of pragmatism unchanged would most likely suggest 
its completest failure-not its failure in practice but its failure to be practiced. This Emersonian self-aversion and willingness to accept one's own failure or outmodedness runs deeper in the American philosophical tradition than pragmatism itself, but in the origins of pragmatism, we see it take on systematic and methodological significance. Even Royce's focus on redemption in The Problem of Christianity is premised on our losses, failures, and sorrows. For Royce our lives are in fact fragmentary and in need of healing. For him, absolute pragmatism can play a cultural role-even if indirectly-in this healing process. These are issues to which we will return in the closing chapter, but not until we have taken a pragmatic, and an Americanly philosophical, attitude into our explorations of some features of our culture. Though not in a fully systematic way, I want to bring this pragmatic attitude to bear on considerations of religious experience, political agency, teaching, literature, and popular culture. In using a varied set of philosophical lenses through which to bring this attitude to bear, I expect that my conclusions will occasionally stand in tension with each other. My hope is more that I can bear witness to a spirit and orientation of the philosophical life in America than that I can achieve a thoroughly consistent set of propositional beliefs.

It would have surprised, if not annoyed, Peirce, James, and Dewey to see the twenty-first century espousing their original thoughts as its own except insofar as those thoughts still provide a clear purchase in our world. This would be a philosophy that had forgotten the fallible and that sought refuge "under the form of a by-gone generation." At the same time, as experimentalists, I believe each would be curious to see which of their thoughts had survived a century's use. The origins of pragmatism, as I have been intentionally overlooking (or putting on hold), despite their core shared outlook, were plural. Arthur Lovejoy famously described thirteen pragmatisms. There were temperamental as well as intellectual differences. Pragmatists are, for pragmatists, not persons committed to propositions, but live creatures with habituated lives that are, in their best form, always undergoing some sort of creative reconstruction. This was the thread that Rorty noticed in his description of the revisability of the self. The 
losses of the origins of pragmatism will therefore likewise be plural and various, and they will be losses having to do with the conduct of life, not merely with the changing of some intellectual "position." Will we embrace James's tolerance of the peculiar? Will we be capable of maintaining Dewey's unflagging faith in education? Will we be able to live with Peirce's in-house quarrel between theory and practice? Are we fated to continue pragmatism's relative blindness to the lives of women and to issues of race?

In a way, like Jonathan Edwards's Calvinistic uncertainty concerning the authenticity of his own conversion, the origins of pragmatism call for an awakening to the need for ongoing awakenings - to the fact that we live in risk, in the precarious, and in the instability of fallibility. They seem to demand of one's character an acknowledgment of the dangers already and always present to us. They also, of course, call forth open responses to the dangers; they demand a melioristic outlook, not on any deductive grounds but on the simple pragmatic claim that only such an outlook offers any possibility of redemption, reconstruction, and recovery. The reality of the possible is perhaps the one ineliminable trace of pragmatism if cultures and philosophies are to move forward even in a halting way. Or, in John McDermott's more ragged but right version: "It's all about possibility." 